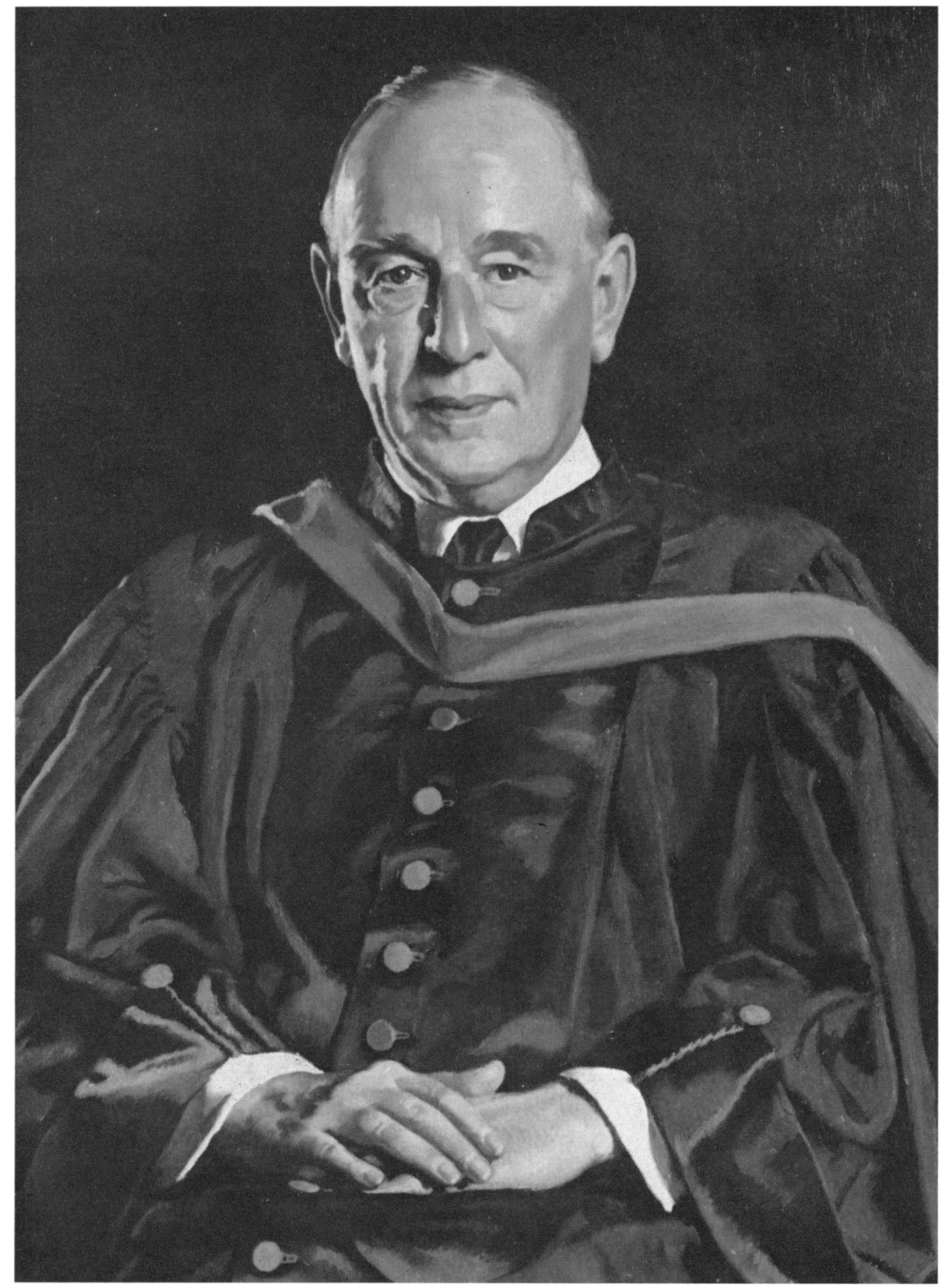

Sir Stewart Duke-Elder, G.C.v.o., F.R.s. 


\section{Sir STEWART DUKE-ELDER, G.C.V.O., F.R.S.}

ON September 30, 1965, Sir Stewart Duke-Elder retired as Director of Research of the Institute of Ophthalmology. The occasion was marked by two main events. At a meeting on July 28, 1965, the Committee of Management had unanimously passed the following resolution.

"On the occasion of the retirement of Sir Stewart Duke-Elder, G.C.V.O., F.R.S., as Director of Research of the Institute of Ophthalmology on September 30, 1965, all members of the Committee of Management desire to place on record a tribute to his magnificent work over the past nineteen years. It is with great regret that they take note of Sir Stewart's retirement, but they recall with gratitude and deep and sincere appreciation, not only his outstanding work, but also his unfailing enthusiasm and guidance at all times.

The reputation of the Institute is now recognized internationally to be of the highest order, due in large measure to the zeal and effort of its Director of Research.

The members of the Committee of Management are delighted and encouraged to know that Sir Stewart's wise counsel will continue to be available and they hope that this may be so for many years to come.

They offer him their affectionate thanks and good wishes for a long and happy retirement."

An illuminated copy of this Resolution, signed by all members of the Committee, was presented to Sir Stewart at a Special Meeting of the Committee of Management held on September 29, and at this same meeting the title of Emeritus Director of Research was conferred on Sir Stewart.

At the unanimous wish of the Committee, Sir Stewart accepted an invitation to become the first President of the Institute.

On the evening of September 29 a Dinner in honour of Sir Stewart and Lady Duke-Elder was held at the Apothecaries Hall, attended by a large number of the present and past staff of both the Institute and the Hospital and their wives, together with the Principal of the University of London, Sir Douglas Logan and Lady Logan, and the Secretary of the Medical Research Council, Sir Harold Himsworth and Lady Himsworth. The Dean, Mr. T. Keith Lyle, in proposing the health of Sir Stewart, said:

My Lord Chairman, Ladies and Gentlemen,

It is a great privilege to undertake the important duty of proposing the toast of Sir Stewart-perhaps you will say "an easy task" for there is so much to be said about this internationally famous and much respected man, but perhaps difficult 
because time will only permit me to pick out some of the highlights of his brilliant career and mention but a few of his remarkable achievements; and priorities are not easy to decide.

This is not a farewell speech for no great actor ever leaves the boards and we look forward to having the benefit of Sir Stewart's help and advice for many years to come.

We are extremely grateful to Sir Stewart for having been sufficiently strongminded to insist on entering the medical profession, and furthermore, for selecting ophthalmology as his special subject, for had he complied with the wishes of his father (a Scottish minister) he would have gone into the Church and would by now, I feel sure, have risen to some exalted ecclesiastical rank such as that of Moderator of the Church of Scotland-for Stewart has a natural aptitude for getting right to the top-not of course in the manner of members of a certain service who are said "gradually to rise to the top like scum on a pond", but by sheer ability, hard work, dogged determination, a keen sense of direction, and the possession of a first-class brain.

Stewart very wisely approached medicine through the medium of an Arts and Science degree, and later became attracted to Ophthalmology largely because of his interest in physiology and physiological optics, becoming involved in research work at University College with Professor Starling in Physiology and with Dr. Drummond in Biochemistry at the instigation of Sir John Parsons (whose portrait hangs in the boardroom at the Institute) who was on the Honorary Staff at Moorfields and U.C.H. and for whom Sir Stewart always had the greatest regard.

I must confess that, until the last war, I hardly knew Sir Stewart, except through the medium of his famous books-The Practice of Refraction and the first two volumes of his well-known text-book (the ophthalmologist's bible).

Sir Stewart is, of course, well known to everyone connected with ophthalmology, but there was an occasion during the War, in which, incidentally, he served with distinction, when his identity was mistaken. It was an occasion when Sir Stewart, then a Brigadier and Consultant in Ophthalmology to the Army, came round to inspect the Eye Departments of the Army Hospitals in the Middle East, and although of exalted rank, he often tended to cut across convention and seek the ophthalmic department of a hospital without going through the approved channels of seeing the C.O. first, and I well remember hearing that on one such occasion he and Brigadier George Scott presented themselves at the door of an Eye Department where a recently appointed and rather tired and disgruntled Australian eye specialist was working. The man looked up and saw two strange figures silhouetted in the doorway, the figure of Brigadier Sir Stewart Duke-Elder dressed in a somewhat loose-fitting bush jacket, a rather baggy pair of army shorts, and a beret sitting at a jaunty angle on the side of his head; standing beside him was the tall, rather angular, and pale-faced Brigadier George Scott, with his peaked service cap pulled down well over his eyes. "Crikey", said the Australian doctor, "who on earth has turned up? Looks like Harry Lauder and Sherlock Holmes."

Now I will refrain from adopting what has been described as the "Who's Who" method of making a speech of this sort, and I will not recite to you in detail the long list of eponymous lectures that Sir Stewart has been invited to give, nor the list of some twenty-four foreign ophthalmological and scientific societies to which he has been elected as an honorary member, the details of some seventeen medals (mostly 
gold) which he has received, not to mention many fellowships, scholarships, and prizes, and the honorary degrees which he has received from many universities. It is a fantastic list, but I believe the honorary degree he prizes the most is the Doctor of Laws of his own University of St. Andrews, the robes of which he is wearing for his portrait.

His long term of service as Surgeon Oculist to King Edward VIII, King George VI, and subsequently to the present Queen, and his appointment as Knight Commander, and later Knight Grand Cross of the Royal Victorian Order, are distinctions upon which he must be congratulated and of which he must be justly proud. His work as Hospitaller of the Order of St. John of Jerusalem and his appointment as Bailiff Grand Cross of the Order call for special comment, and the work he did in planning most successfully the new hospital in Jordan and the research work relating to trachoma in connexion with it has been of the most profound importance.

As far as the Institute of Ophthalmology is concerned there are three important spheres in which Sir Stewart has rendered unique service-these, although separate entities, are closely concerned with each other.

\section{(a) The Institute}

It is perhaps not generally known that the amalgamation of three of the eye hospitals in London and the formation of the Institute of Ophthalmology were put into action a year before the National Health Service was started and this was almost entirely due to the efforts of Sir Stewart, encouraged and assisted by Sir John Parsons and Miss Ida Mann. In fact, as long ago as 1937 Sir Stewart had started to make plans for an Institute of Ophthalmology in London.

Although before the war some valuable research in ophthalmology had been done in the British Isles, mainly of a clinical nature, there was no centre where properly organized work was undertaken. This was especially true of ocular pathology and the basic sciences.

As Director of Research for a period of no less than nineteen years, Sir Stewart has organized and co-ordinated the research work in the various departments of the Institute. He has given much of his time to arranging projects of research, interviewing would-be research workers, deciding as to their potential, encouraging those who needed encouragement, planning the best way to use the Institute's slender financial resources, and persuading charitable organizations to make generous allowances-in fact he has been the driving force behind the entire Institute (the "tiger in the tank", as it were) and everyone who has had the privilege (and indeed it is a privilege) of working at the Institute must feel deeply grateful to him and will experience an acute sense of loss when he no longer reigns, so to speak, as "Head Master".

We are indeed proud to belong to the Institute of Ophthalmology. The results of the work at the Institute have repercussions all over the world of ophthalmology, and the Institute has been the means of training numbers of young ophthalmologists in the correct approach to research methods and of encouraging them to continue to make some useful contribution towards the science of ophthalmology, and not only to become expert technicians in ophthalmic surgery. I do not wish, however, to belittle the importance of surgical expertise. 
It was largely in connexion with his work at the Institute (which now enjoys an international reputation) that he won a distinction which nowadays is rarely conferred upon clinicians in the medical profession and more rarely still upon ophthalmologists, namely, the Fellowship of the Royal Society.

In fact, Sir Stewart is only the second ophthalmologist to gain this distinction in the present century, the other one being the late Sir John Parsons.

\section{(b) British Ophthalmology}

Sir Stewart has almost certainly done more to raise the standard of British ophthalmology than anyone since Sir William Bowman. It was Sir Stewart who persuaded the Royal College of Surgeons (and they took some persuading too!) to establish a special final Fellowship examination in ophthalmology.

There had, of course, been such an examination previously, but it was of little practical value because of the somewhat Gilbertian fact that no one was permitted to take it until he had passed the ordinary examination for the final fellowship in general surgery. Thus it had very little practical value. Probably the only examination in which the pass rate was 100 per cent. but the number of people who took the examination was small-to be exact precisely one!

The establishment of the F.R.C.S. in ophthalmology was an enormous step forward and the Fellowship in Ophthalmology is now regarded as being one of the accepted requirements for a consultant appointment.

Incidentally, it was Sir Stewart who was one of those who initiated the examination for the "Diploma in Ophthalmology" or, as it was then called, the "Diploma of Ophthalmological Medicine and Surgery", for which he was one of the examiners for many years. My father, who was also one of the original examiners, always enjoyed examining with Sir Stewart.

In connexion with his efforts to enhance British ophthalmology, his Text-book must be given a place on a pedestal!

It is quite fantastic, or in modern phraseology, it is fabulous-or as Jimmy Doggart once said, "It is quite indecent that one man could produce a book of that immense size and value." A book that no ophthalmologist can afford to be without-I refer to the first edition of his Text-book for which he was awarded the Fothergillian Prize of the Medical Society of London for the best contribution to medical literature-not, I would point out, to ophthalmic literature-no, no, nothing so parochial, but to the whole of medical literature.

I am told that when Sir Stewart was busily engaged in writing this book before the War he frequently worked so late and started so early that when he went upstairs to bed he used to meet himself coming down in the morning.

And I must also mention his work on behalf of the British Journal of Ophthalmology which now enjoys a high reputation and popularity (in spite of the increased charges!).

\section{(c) International Ophthalmology}

Although many countries can boast of learned professors of ophthalmology and men who have dedicated themselves to research work in some particular field, there is no one who is so universally respected and revered as a leader of ophthalmology as 
Sir Stewart. He served as President of the International Council of Ophthalmology for a long period and on retiring from the Chair was unanimously elected as an honorary life President.

For many years he has entertained large numbers of foreign ophthalmologists at his home and his hospitality, generosity, and friendliness are well known. He is the very antithesis of the Englishman I knew who, when an American was introduced to him who grasped his hand and said "Glad to meet you", replied "WHY?", but then Sir Stewart is a warm-hearted and friendly Scot.

Stewart is a very approachable person with a delightfully informal manner. With his charming smile and puckish sense of humour he at once puts strangers at their ease. He also has the ability to listen and to take a friendly interest in the personal problems of his colleagues. His advice is invariably sound and given with careful thought. His judgement and sense of timing are quite amazing and based on a profound knowledge of his subject. He is a man of extraordinary capability and he has the power of cheerfully over-riding difficulties which to some would seem insurmountable. I have often noticed him at committee meetings sitting silently whilst others have argued at some length and then quite suddenly and quite quietly, rather like a conjuror producing a rabbit out of a top hat, he sums the situation up with a wise remark showing foresight and judgement and rendering further discussion quite unnecessary.

But perhaps he is seen at his best in what may be called "back-stage negotiations" where, over a friendly chat and a drink, he is adept at persuading people to come round to his point of view.

His advice at all committees is invariably sound,

On complicated problems he can lucidly expound,

He knows everybody's job of work and what each one has done,

$\mathrm{He}$ can be very serious or he can be full of fun,

And although he never talks about himself or his position

It's clear he is a genius with a curious intuition,

There's no doubt about his place, the rest are "also ran",

He's done more for ophthalmology than any other man.

No eulogy about any great man is complete without reference to his wife, for happy home circumstances and the love and support and advice from a wife play an important role in the life of most professional men and in this respect he is remarkably fortunate, for who can imagine a more charming person than Phyllis. In the words of the song in "My Fair Lady", she has "the milk of human kindness by the quart in every vein". She has always taken an important part in all his activities, she is an ideal hostess, never forgetting the names of newcomers, nor omitting to cater for their special needs.

Since it is nowadays impossible to think or speak of any subject without bringing in the word image, I would like, in proposing this toast, to say that Stewart and Phyllis provide an image of the ideal ophthalmologist and his wife.

They are indeed a unique pair of the most delightful people! Few people can ever have done so much for so many for so long as they have.

My Lord Chairman, Ladies and Gentlemen, I give you the toast of Stewart and Phyllis Duke-Elder. 
The Rt. Hon. the Earl of Rothes, the Chairman of the Committee of Management of the Institute, presented to Sir Stewart a portrait of himself which had been subscribed to by a large number of past and present staff and students and friends. The list of subscribers represented 36 different countries and demonstrated the esteem and affection in which Sir Stewart is held.

The frontispiece is taken from the portrait of Sir Stewart, painted by Mr. Edward Halliday, which was presented at the dinner. (Photograph by Paul Lamb, London.) 